\title{
ARTICLE \\ Ginkgo biloba extracts prevent aortic rupture in angiotensin II-infused hypercholesterolemic mice
}

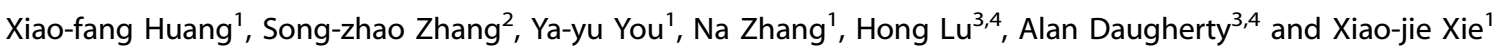

\begin{abstract}
Abdominal aortic aneurysms (AAAs) are a chronic vascular disease characterized by pathological luminal dilation. Aortic rupture is the fatal consequence of AAAs. Ginkgo biloba extracts (GBEs), a natural herb extract widely used as food supplements, drugs, and cosmetics, has been reported to suppress development of calcium chloride-induced AAAs in mice. Calcium chloride-induced AAAs do not rupture, while angiotensin II (Angll)-induced AAAs in mice have high rate of aortic rupture, implicating potentially different mechanisms from calcium chloride-induced AAAs. This study aimed to determine whether GBE would improve aortic dilation and rupture rate of Angll-induced AAAs. Male apolipoprotein E (apoE) -/- mice were infused with Angll and administered either GBE or its major active ingredients, flavonoids and ginkgolides, individually or in combination. To determine the effects of GBE in mice with established AAAs, male apoE-/- mice were firstly infused with Angll for 28 days to develop AAAs, and then administered either GBE or vehicle in mice with established AAAs, which were continuously infused with Angll for another 56 days. GBE, but not the two major active components separately or synergistically, prevented aortic rupture, but not aortic dilation. The protection of GBE from aortic rupture was independent of systolic blood pressure, lipid, and inflammation. GBE also did not attenuate either aortic rupture or progressive aortic dilation in mice with established AAAs. GBE did not reduce the atherosclerotic lesion areas, either. In conclusion, GBE prevents aortic rupture in Angll-infused hypercholesterolemic mice, but only in the early phase of the disease development.
\end{abstract}

Keywords: abdominal aortic aneurysm; angiotensin; hypercholesterolemia; ginkgo biloba extracts; flavonoids; ginkgolides

Acta Pharmacologica Sinica (2019) 40:192-198; https://doi.org/10.1038/s41401-018-0017-7

\section{INTRODUCTION}

Abdominal aortic aneurysms (AAAs) are a chronic vascular disease characterized by progressive luminal dilation of the abdominal aorta. Aortic rupture is the fatal consequence of AAAs. The acute mortality, defined as death before reaching a hospital or during first admission, was $\sim 30 \%$ for ruptured aortic aneurysm [1]. In a study in Finnish population [2], about $60 \%$ patients with aortic rupture reached the hospital and $50 \%$ finally underwent emergency surgery. When including operative mortality, $77 \%$ of patients with ruptured AAAs died. Another report showed that inhospital mortality was $53 \%$ in the USA and $66 \%$ in England [3]. No non-invasive therapy, except for surgery, is of any help once an aortic aneurysm has ruptured. Therefore, there is a dire need to prevent aortic rupture with non-invasive approaches such as medications.

There is no proven medical therapy that can prevent the expansion or rupture of AAAs. Effective pharmacological treatment for AAAs is not available due to the paucity of defined mechanisms underlying the pathological process and the nature of aortic rupture. Angiotensin II (Angll) is the primary bioactive peptide of the rennin angiotensin system that plays a critical role in many cardiovascular diseases [4]. Subcutaneous infusion of
Angll into mice induces the development of AAAs. Angll-induced AAAs recapitulate not only many pathological features of human AAAs, including elastin breaks, extracellular matrix degradation, inflammatory cells accumulation, and aortic rupture [4], but etiological risk factors, such as male gender, aging, and long history of smoking [5]. In this animal model, it has reported that c-Jun N-terminal kinase inhibitor (SP600125) [6] and anti-oxidants (a-tocopherol and $\beta$-carotene) [7] regressed established AAAs, while renin inhibitor (aliskiren) [8] and cyclooxygenase-2 inhibitor (celecoxib) [9] prevented AAA progression. In contrast, there is rare report of pharmacological treatment for aortic rupture.

Ginkgo biloba extracts (GBEs), a natural herb extract, are widely used as food supplements, drugs, and cosmetics. GBE, known as the "maidenhair tree," is commonly prescribed as traditional Chinese medicine for patients with cardiac-cerebral vascular diseases, even as preventive food supplements to healthy adults. It has been consumed as one of the top Chinese herb extracts [10] and the best-selling herbal remedy in the USA [11]. Its main ingredients that are considered to have biological activities include flavonoids and ginkgolides [12] GBE protects against inflammation, oxidative stress, platelet aggregation, matrix metalloproteinase (MMP) activation, and endothelial dysfunction

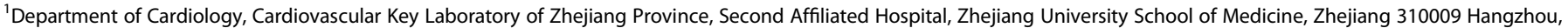

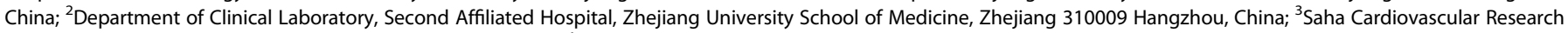
Center, University of Kentucky, Lexington, KY 40536, USA and ${ }^{4}$ Department of Physiology, University of Kentucky, Lexington, KY 40536, USA

Correspondence: Xiao-jie Xie (xiexj@zju.edu.cn)

These authors contributed equally: Xiao-fang Huang, Song-zhao Zhang.

Received: 26 August 2017 Accepted: 11 February 2018

Published online: 18 May 2018 
$[13,14]$. It has been reported that GBE suppresses the development of calcium chloride-induced AAAs through antiinflammation and MMP-mediated mechanisms [13]. However, there has no report to indicate that AAA ruptures in this mouse model. Since Angll-induced AAAs may have potentially different mechanisms from calcium chloride-induced AAAs, we sought first to determine whether GBE exerted a protective effect against the development of AAAs and aortic rupture in hypercholesterolemic mice infused with Angll. Then, GBE major active ingredients, flavonoids and ginkgolides, were administered individually or in combination in Angll-infused hypercholesterolemic mice to interpret the protective mechanisms.

\section{MATERIALS AND METHODS}

Materials

Angiotensin II acetate (Angll) was purchased from Bachem (catalog no. H1705, Torrance, CA). Osmotic mini-pumps were purchased from Alzet (Model 2004; Durect, Cupertino, CA, USA). GBE (Tian-bao-ning) and its major active ingredients, flavonoids and ginkgolides, were kindly provided by Zhejiang Conba Pharmaceutical Co., Ltd. (Hangzhou, Zhejiang, China).

\section{Mouse housing condition and diets}

All animal studies were performed with the approval of Zhejiang University Institutional Animal Care and Use Committee.

One hundred and five male apolipoprotein E-deficient (apoE $-/-$ ) mice (8-12 weeks old) on C57BL/6 background weighing $20-25 \mathrm{~g}$ were used in the study. Mice were maintained under specific pathogen-free conditions at room temperature $\left(22^{\circ} \mathrm{C}\right)$ with a $12 \mathrm{~h}$ light/dark cycle and fed normal laboratory diet. The mice were purchased from Cavens Laboratory Animal Corporation (Changzhou, Jiangsu, China).

Osmotic mini-pump implantation and drug administration Angll (1000 $\mathrm{ng} / \mathrm{kg}$ per min) was dissolved in sterile saline and infused subcutaneously via mini-osmotic pumps as described previously $[15,16]$. Mice were inspected daily and weighed weekly. Systolic blood pressure was measured in conscious mice using a computerized tail cuff (CODA 6+; Kent Scientific, Torrington, CT, USA). All mice were acclimated to the system for 1 week before the start of the study. Ten pressure cycles were used to obtain daily mean systolic blood pressures after acclimation, as described previously [16].

In the first 1-month study, male apoE-/- mice were randomly divided into two groups, administered with GBE or vehicle 7 days before Angll infusion and throughout the whole study. GBE was dissolved in drinking water at a dose of $100 \mathrm{mg} / \mathrm{kg}$ per day, prepared fresh daily and administered 7 days before and during Angll infusion.

In the second 1-month study, male apoE-/- mice were randomly divided into four groups, administered with vehicle or GBE ingredients, separately or synergistically 7 days before Angll infusion and throughout the whole study. GBE major active ingredients, flavonoids ( $40 \mathrm{mg} / \mathrm{kg}$ per day) and ginkgolides (10 $\mathrm{mg} / \mathrm{kg}$ per day), individually or in combination was dissolved in drinking water and administered, respectively.

In the 3-month study, male apoE-/- mice were firstly infused with Angll for 28 days to develop AAAs. At the 28-day interval, surviving mice were verified by ultrasonography and stratified into two groups with equivalent sized AAAs. One group was provided with drinking water alone (vehicle), and the other group was administered with GBE ( $100 \mathrm{mg} / \mathrm{kg}$ per day). Immediately before treatment, mice with established AAAs were implanted with new mini-osmotic pumps at day 28 and the pumps were replaced at day 56 to permit continuous delivery of Angll for another 56 days, as described previously [17].
Necropsy

Necropsy was performed for all mice that died prior to termination. Aortic rupture was defined as observation of blood clots in either the thoracic cavity (thoracic aortic rupture) or retroperitoneal cavity (abdominal aortic rupture).

Quantification of abdominal aortic dilation and atherosclerosis Maximal dimensions and areas of suprarenal lumen were monitored at selected intervals (day $0,28,56$, and 84) by a high-frequency ultrasound imaging system (Visualsonics Vevo 2100; Toronto, Ontario, CA) as described previously [15-18]. Incidence of AAA was defined by either (1) $50 \%$ or more increase of the maximal diameter in the suprarenal aortic region as compared to the baseline or (2) death due to abdominal aortic rupture $[15,16]$.

At termination, right atrium was cut open, and saline was perfused through the left ventricle to remove blood in the aorta. Subsequently, aortas were dissected and placed in 10\% neutrally buffered formalin. After fixation, periaortic adventitia was removed thoroughly. Maximal width of suprarenal aortas was measured ex vivo as a parameter for AAA quantification using Image-Pro software (Media Cybernetics, MD, USA). Atherosclerosis was assessed in the intima of aortic arches by an en face technique as described previously [15-18]. Quantitative analysis of atherosclerosis was performed using Image-Pro software as described previously [15-18]. All the data were quantified by two observers that were blinded to the study design.

Serum measurements and histological staining

Serum total cholesterol concentrations were determined using an enzymatic assay kit (294-65801, Wako Chemical, Japan) as described previously [17]. Serum cytokines and enzymes were measured with ELISA kits according to manufacturer's recommendation, including monocyte chemoattractant protein 1 (MCP-1, MJE00), interleukin 6 (IL-6, M6000B), total matrix metalloproteinase 2 (MMP-2, MMP200), and total matrix metalloproteinase 9 (MMP-9, MMPT90) (R\&D Systems Minneapolis, MN, USA).

Abdominal aortas containing AAAs were serially cross-sectioned ( $10 \mu \mathrm{m}$ thick per section) from the proximal to the distal as described previously [15-18]. Elastin was identified in selected sections with Verhoeff-van Gieson stains as described previously (HT25A, Sigma, St. Louis, MO, USA) [15].

Statistical analyses

Means and SEM were calculated for each parameter. Data were tested for use of parametric or non-parametric post hoc analysis and then analyzed by Student's $t$ test or Mann-Whitney rank sum test using SigmaPlot (version 13.0, SYSTAT Software Inc., Sao Jose, CA, USA) or STATA (version 12.0, Stata Corp LLC, TX, USA). Incidence of AAA and rate of aortic rupture were analyzed using Fisher's exact test. For survival rate analysis, log-rank (Mantel-Cox) test was used. A $P$ value of $<0.05$ was considered to be statistically significant.

\section{RESULTS}

GBE prevented aortic rupture, but not aortic dilation in Angllinfused mice

To determine effects of GBE on Angll-induced AAAs, male apoE $-/-$ mice were infused with Angll and administered either vehicle or GBE through drinking water. Angll infusion for 28 days induced an increase of systolic blood pressure in apoE-/- mice from $124.7 \pm 2.8 \mathrm{mmHg}$ to $152.7 \pm 4.3 \mathrm{mmHg}$, that was not influenced by administration of GBE $(159.5 \pm 6.8 \mathrm{mmHg}$ at day 28). Survival rate of mice administered GBE was higher compared to mice infused with Angll alone (95\% vs. 63\%) (Fig. 1a), which was attributed to much less aortic rupture rate in mice administered 

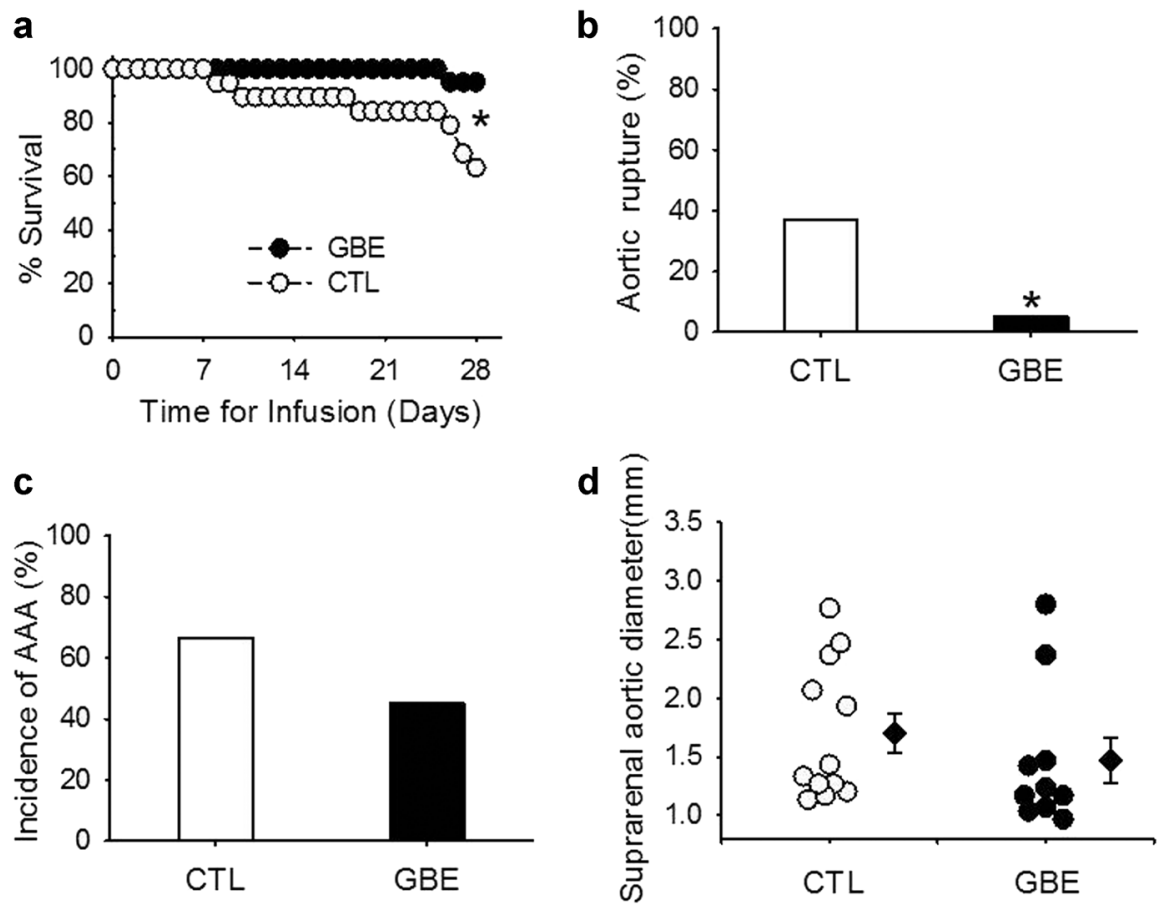

Fig. 1 GBE reduced aortic rupture-induced death in Angll-infused mice. a Kaplan-Meier curves of survival. (log-rank analysis, ${ }^{*} P=0.015$ vs. CTL). b Death due to aortic rupture was confirmed with necropsy (Fisher's exact test, ${ }^{*} P=0.02$ vs. CTL). c Incidence of AAAs defined by either (1) $50 \%$ or more increase of the maximal diameter in the suprarenal aortic region as compared to the baseline or (2) death due to abdominal aortic rupture. d Maximal external width of the suprarenal aortas was measured by Image-Pro Plus software. All values were presented as the means \pm SEM. Values of individual mice were represented as circles, diamonds were means, and bars were SEM. GBE represented Ginkgo biloba extracts $(n=20)$, CTL represented the control $(n=19)$

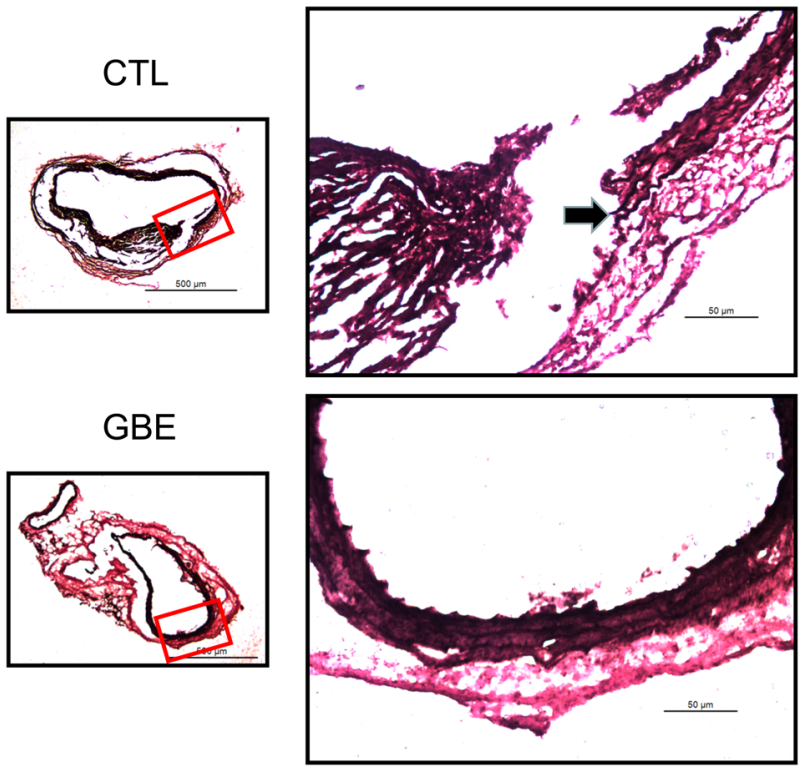

Fig. 2 GBE attenuated elastin breakdown in Angll-induced mice. The images shown are representative aneurysm sections with Verhoeff-van Gieson staining. Elastin disruption and medial rupture seen at arrows. GBE represented Ginkgo biloba extracts, CTL represented the control

GBE (5\% vs. 36.8\%) (Fig. 1b). However, GBE did not reduce incidence of Angll-induced AAAs (45\% vs. 66.7\%) (Fig. 1c). Compared with those of the control $(1.66 \pm 0.16 \mathrm{~mm})$, GBE administration did not decrease maximal aortic diameters of suprarenal aortas $(1.47 \pm 0.20 \mathrm{~mm})$ in Angll-infused mice, either (Fig. 1d). Administration of GBE did not decrease percent lesion areas on the intimas of aortic arches compared with mice administered vehicle $(2.57 \pm 1.32 \%$ vs. $7.98 \pm 3.12 \%)$.

Several of the aortic aneurysms were sectioned at $10 \mu \mathrm{m}$ throughout the entire bulbous area of the abdominal aorta. More profoundly disrupted and fragmented elastic lamellae were seen in the aortas of mice infused with Angll alone compared to those administered GBE (Fig. 2). Serum concentrations of total cholesterol, proinflammatory cytokines and enzymes were measured by enzymatic assay kits, respectively. Administration of GBE did not reduce serum total cholesterol concentrations in Angllinfused mice ( $207 \pm 18 \mathrm{mg} / \mathrm{dl}$ vs. $262 \pm 31 \mathrm{mg} / \mathrm{dl}$ ) (Fig. 3a). GBE administration did not alter serum concentrations of MCP-1 (119.3 $\pm 12.1 \mathrm{pg} / \mathrm{ml}$ vs. $145.5 \pm 20.5 \mathrm{pg} / \mathrm{ml})$, IL-6 $(8.6 \pm 4.9 \mathrm{pg} / \mathrm{ml}$ vs. $5.4 \pm$ $3.1 \mathrm{pg} / \mathrm{ml}), \mathrm{MMP}-2(89.4 \pm 7.4 \mathrm{ng} / \mathrm{ml}$ vs. $99.8 \pm 9.9 \mathrm{ng} / \mathrm{ml})$, or MMP-9 $(93.8 \pm 6.4 \mathrm{ng} / \mathrm{ml}$ vs. $100.0 \pm 7.2 \mathrm{ng} / \mathrm{ml}$ ), either (Fig. 3).

GBE active ingredients did not prevent aortic rupture in Angllinfused mice

To interpret the potential effective components of GBE on aortic rupture, we administered both individual and combined active ingredients through drinking water in male apoE-/- mice 7 days before Angll infusion and throughout the whole study. The 28-day infusion of Angll induced an average $28 \mathrm{mmHg}$ increase of systolic blood pressure in apoE-/- mice, that was not influenced by administration of GBE major active ingredients, individually or synergistically (the average $30.9 \mathrm{mmHg}, 24.5 \mathrm{mmHg}$, and $31.7 \mathrm{mmHg}$ increase of systolic blood pressure in apoE-/- mice administered with flavonoids, ginkgolides, and their combination, respectively). During the 28 days of Angll infusion, compared with those administered vehicle $(37 \%, 7 / 19)$ or $\operatorname{GBE}(5 \%, 1 / 20)$ (Fig. 1a), the mortalities of mice administered with flavonoids, ginkgolides, and their combination were $10 \%(1 / 10), 20 \%(2 / 10)$, and $10 \%$ $(1 / 10)$, respectively (Fig. $4 a, b)$, which were attributed to aortic rupture. Furthermore, neither individual nor combined 

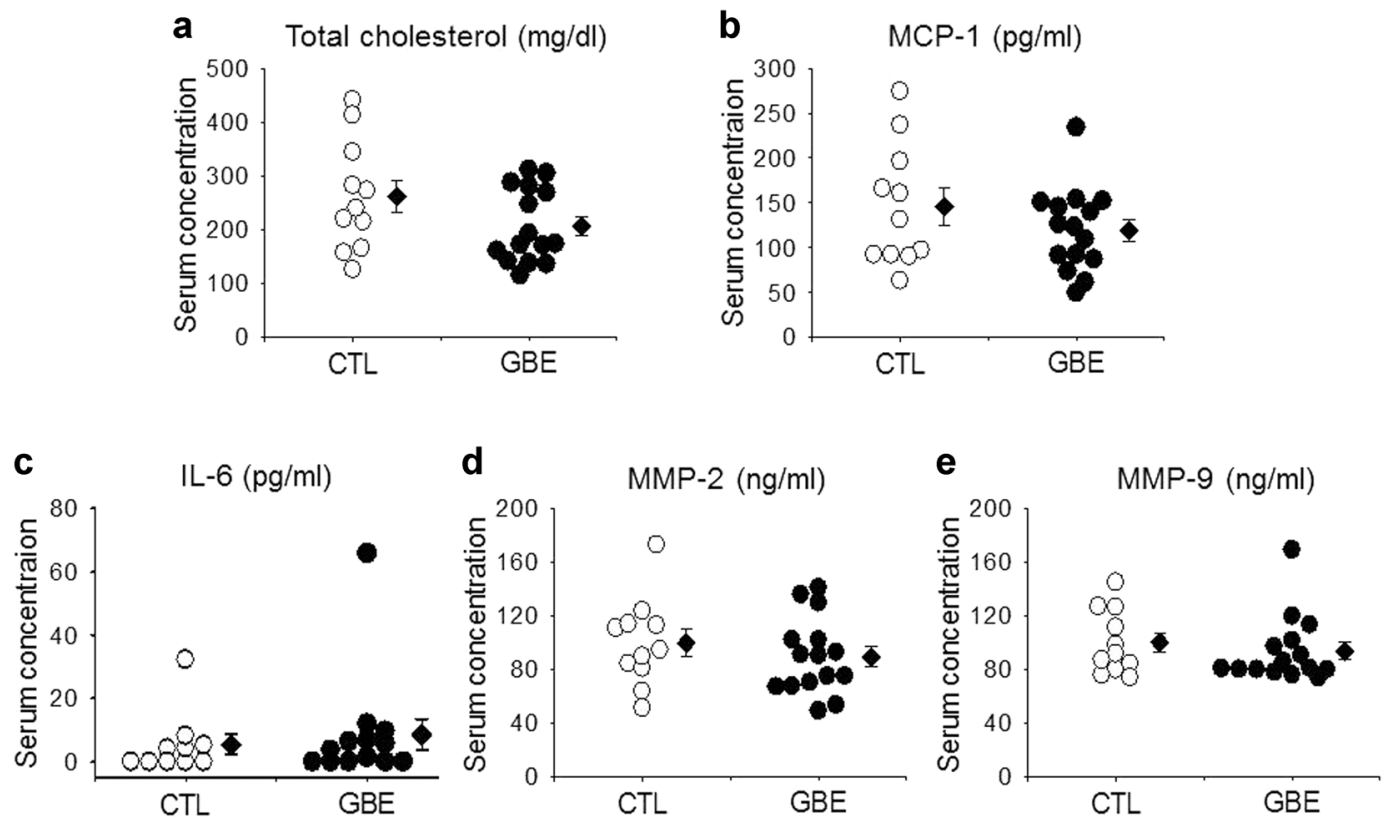

Fig. 3 GBE did not reduce serum concentrations of total cholesterol, proinflammatory cytokines, and MMPs. Serum concentrations of total cholesterol (a), MCP-1(b), IL-6 (c), MMP-2 (d), and MMP-9 (e) in apoE-/- mice infused with Angll for 28 days. All values were presented as the means \pm SEM. Values of individual mice were represented as circles, diamonds were means, and bars were SEM. GBE represented Ginkgo biloba extracts $(n=15)$, CTL represented the control $(n=11)$

a

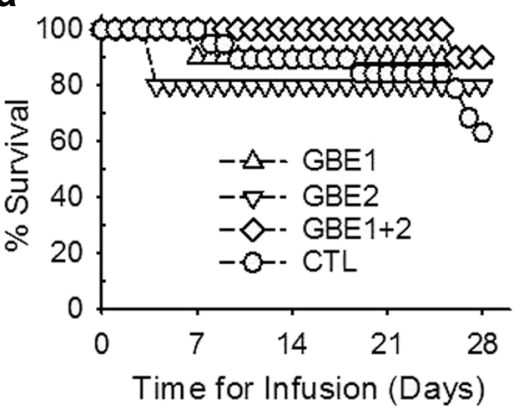

C

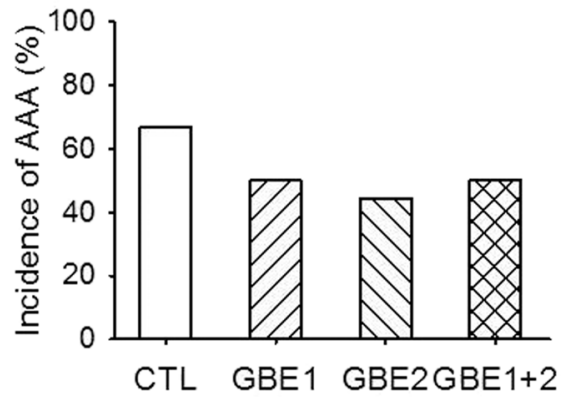

b

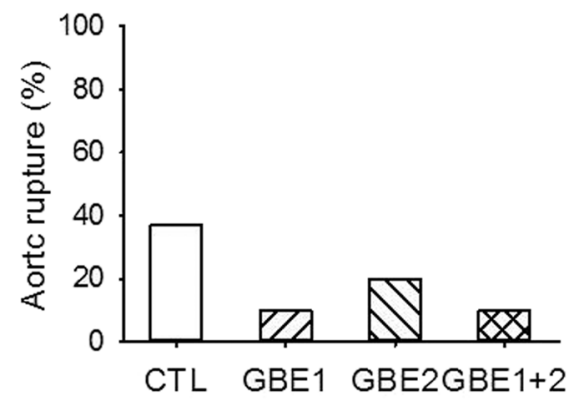

d

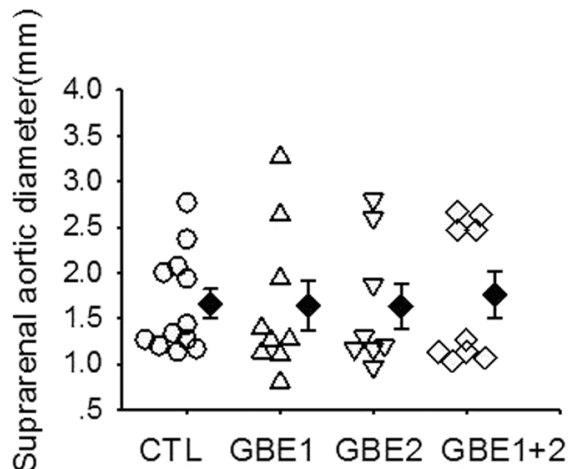

Fig. 4 GBE major active ingredients did not prevent development of Angll-induced AAAs. a Kaplan-Meier curves of survival between vehicle and GBE major active ingredients. b Death due to aortic rupture was confirmed with necropsy. c Incidence of AAAs defined by either (1) $50 \%$ or more increase of the maximal diameter in the suprarenal aortic region as compared to the baseline or (2) death due to abdominal aortic rupture. d Maximal external width of the suprarenal aortas was measured by Image-Pro Plus software. All values were presented as the means \pm SEM. Values of individual mice were represented as circles, diamonds are means, and bars were SEM. GBE1 represented flavonoids, GBE2 represented ginkgolides, and GBE1 +2 represented the combined administration of flavonoids and ginkgolides ( $n=10$ per group). CTL represented the control $(n=19)$ 

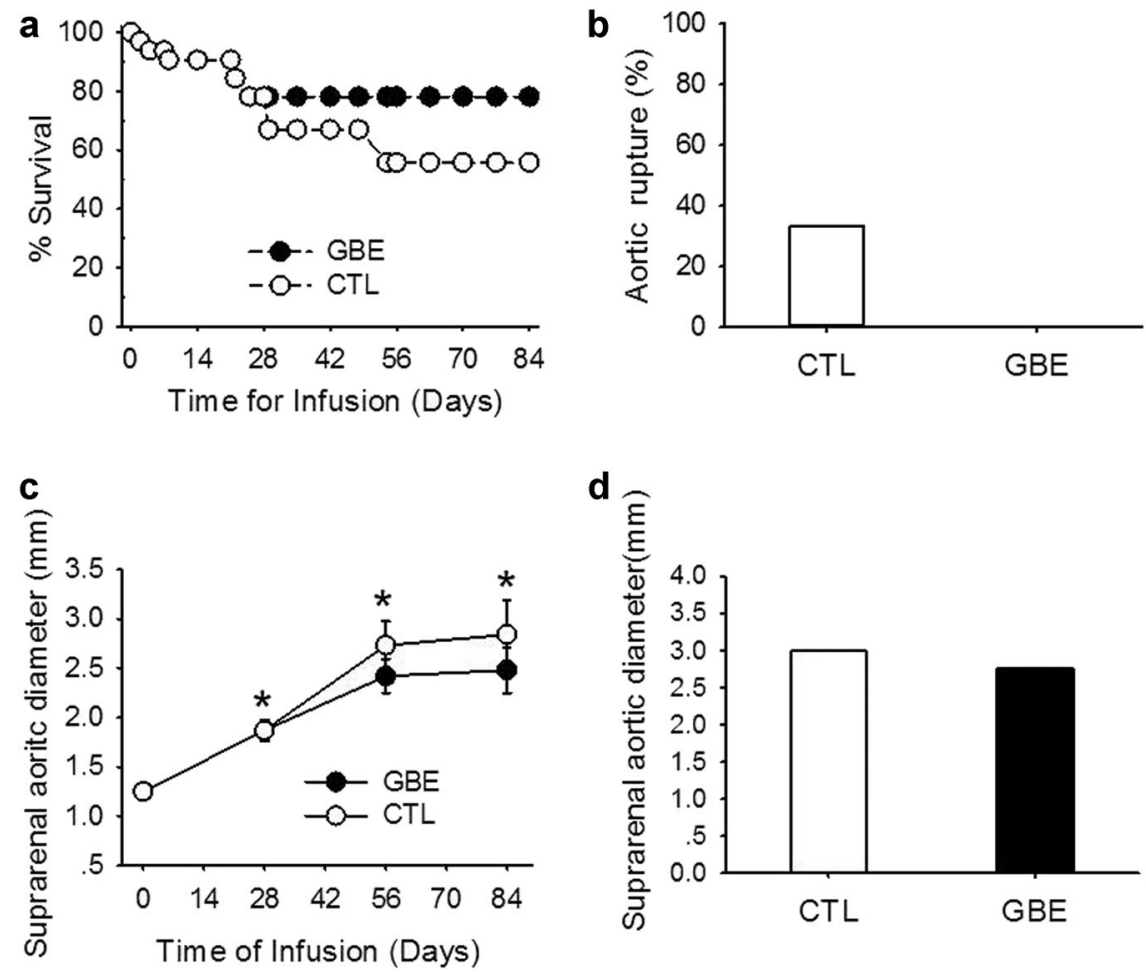

Fig. 5 GBE did not prevent aortic rupture and progressive aortic dilation in Angll-infused mice. a Kaplan-Meier curves of survival ( $n=32$ ). b Death due to aortic rupture was confirmed with necropsy. c Maximal diameter of suprarenal aortas was determined by in vivo ultrasound imaging and measured by Image-Pro Plus software (Mann-Whitney rank sum test, ${ }^{*} P<0.001$ vs. day 0 ). All values were presented as the means \pm SEM. d Maximal external width of the suprarenal aorta was measured by Image-Pro Plus software. GBE represented Ginkgo biloba extracts $(n=7)$, CTL represented the control $(n=7)$

administration of flavonoids and ginkgolides reduced incidence of Angll-induced AAAs $(50 \%, 44 \%$, and $50 \%$ vs. $67 \%$ in control) (Fig. 4c). Compared with those of the control $(1.66 \pm 0.16 \mathrm{~mm})$, neither individual nor combined administration of flavonoids and ginkgolides decreased maximal aortic diameters of suprarenal aortas $(1.64 \pm 0.27 \mathrm{~mm}, 1.63 \pm 0.25 \mathrm{~mm}$, and $1.76 \pm 0.25 \mathrm{~mm}$, respectively) (Fig. 4d). Individual or combined administration of flavonoids and ginkgolides did not decrease percent lesion areas on the intimas of aortic arches compared with mice administered vehicle, either $(1.09 \pm 0.27 \%, 1.51 \pm 0.26 \%$ and $0.95 \pm 0.71 \%$ vs. $1.27 \pm 0.31 \%$ ). Individual or combined administration of flavonoids and ginkgolides did not reduce serum total cholesterol concentrations in Angll-infused mice $(179 \pm 14 \mathrm{mg} / \mathrm{dl}, 197 \pm 19 \mathrm{mg} / \mathrm{dl}$, and $235 \pm 23 \mathrm{mg} / \mathrm{dl}$ vs. $247 \pm 23 \mathrm{mg} / \mathrm{dl}$ ). Moreover, Individual or combined administration of flavonoids and ginkgolides did not alter serum concentrations of MCP-1 $(206.7 \pm 16.4 \mathrm{pg} / \mathrm{ml}, 158.6 \pm$ $29.3 \mathrm{pg} / \mathrm{ml}$, and $99.2 \pm 12.0 \mathrm{pg} / \mathrm{ml}$ vs. $119.7 \pm 12.1 \mathrm{pg} / \mathrm{ml}$ ), IL-6 $(17.3 \pm 7.2 \mathrm{pg} / \mathrm{ml}, 18.1 \pm 7.3 \mathrm{pg} / \mathrm{ml}$, and $3.5 \pm 1.6 \mathrm{pg} / \mathrm{ml}$ vs. $6.0 \pm$ $1.9 \mathrm{pg} / \mathrm{ml}), \mathrm{MMP}-2(92.2 \pm 5.6 \mathrm{ng} / \mathrm{ml}, 112.2 \pm 18.2 \mathrm{ng} / \mathrm{ml}$, and 102.2 $\pm 9.1 \mathrm{ng} / \mathrm{ml}$ vs. $111.7 \pm 6.1 \mathrm{ng} / \mathrm{ml})$, or MMP-9 $(107.7 \pm 10.8 \mathrm{ng} / \mathrm{ml}$, $86.9 \pm 7.0 \mathrm{ng} / \mathrm{ml}$, and $83.2 \pm 3.9 \mathrm{ng} / \mathrm{ml}$ vs. $91.1 \pm 7.8 \mathrm{ng} / \mathrm{ml})$, either.

GBE did not prevent the progression of established AAAs

Since patients only seek for medical treatment after an AAA is diagnosed, we determined whether GBE prevented aortic rupture or progression of established AAAs. Male apoE-/- mice were infused with Angll for 28 days prior to administration of GBE. Mice with established AAAs, as confirmed by ultrasonography [16], were stratified into two groups to receive either vehicle or GBE for 56 days. Angll induced an increase of systolic blood pressure from $120.0 \pm 1.5 \mathrm{mmHg}$ to $144.7 \pm 11.6 \mathrm{mmHg}$, that was not influenced by administration of GBE $(149.0 \pm 4.0 \mathrm{mmHg}$ at day 84$)$. During the 84 days of Angll infusion, there was no difference of mortalities between the GBE and control groups (56\% vs. 78\%) (Fig. 5a). GBE did not prevent the aortic rupture in established AAAs $(0 \%$ vs. 33.3\%) (Fig. 5b). Angll induced a persistent increase of suprarenal aortic diameter from $1.25 \pm 0.02 \mathrm{~mm}$ to $2.84 \pm 0.35 \mathrm{~mm}$ in apoE-/mice (Fig. 5c). However, GBE did not prevent either the progressive aortic dilation $(2.48 \pm 0.23 \mathrm{~mm}$ vs. $2.84 \pm 0.35 \mathrm{~mm}$ ) (Fig. $5 \mathrm{c}$ ) or maximal external diameter of suprarenal aorta $(2.75 \pm 0.33 \mathrm{~mm}$ vs. $2.99 \pm 0.25 \mathrm{~mm}$ ) (Fig. $5 \mathrm{~d}$ ). GBE did not attenuate the atherosclerotic lesions during the 84 days of Angll infusion in apoE-/- mice (15.11 $\pm 2.42 \%$ vs. $16.00 \pm 1.12 \%$ ). Administration of GBE did not reduce serum total cholesterol concentrations in mice infused with Angll for 3 months $(198 \pm 39 \mathrm{mg} / \mathrm{dl}$ vs. $215 \pm 36 \mathrm{mg} / \mathrm{dl})$. GBE administration did not alter serum concentrations of MCP-1 $(220.4 \pm 69.2 \mathrm{pg} / \mathrm{ml}$ vs. $172.2 \pm 22.4 \mathrm{pg} / \mathrm{ml})$, IL-6 $(17.2 \pm 4.2 \mathrm{pg} / \mathrm{ml}$ vs. $5.5 \pm 3.8 \mathrm{pg} / \mathrm{ml})$, MMP-2 $(68.5 \pm 14.2 \mathrm{ng} / \mathrm{ml}$ vs. $52.0 \pm 9.7 \mathrm{ng} / \mathrm{ml})$, or MMP-9 $(94.8 \pm$ $10.7 \mathrm{ng} / \mathrm{ml}$ vs. $71.9 \pm 7.9 \mathrm{ng} / \mathrm{ml})$, either.

\section{DISCUSSION}

Aortic rupture is a complex biological process involving biochemical, cellular, proteolytic, and biomechanical factors [19]. Although aortic diameter has been used as the major criterion of surgery, how precisely aortic dilation predicts risk for aortic rupture is unclear $[20,21]$. Our study showed that GBE had no effect on aortic dilation in Angll-induced AAAs, but it prevented aortic rupture. There are reports that GBE protects against endothelial dysfunction [22], inflammation [23], and MMP expression [13]. Platelets deposition has also been found in human AAAs tissue, and clopidogrel, a platelet $\mathrm{P} 2 \mathrm{Y} 12$ receptor inhibitor, suppresses the development of Angll-induced AAAs [24]. Different from the inhibiting site of clopidogrel, GBE contains three specific antagonists, named as ginkgolides $A, B$, and $C$, which contribute to inhibiting the metabolism of platelet activating factor (PAF) on 
platelet membrane [22]. GBE elicits anti-inflammation effect, such as decreasing serum intracellular and vascular adhesive molecules and P-selectin, which is consistent with our previous study of another Chinese traditional medicine on Angll-induced AAAs [17]. Multiple effects of GBE might be involved in its protection against aortic rupture. As an oral medicine easily available with no apparent side effects, GBE may be a promising prophylactic approach for aortic rupture in patients suffered with AAAs.

Herbal medicine has been widely used in China as well as other Asian countries for treatment of cardiovascular diseases for hundreds of years. However, the mechanistic actions of Chinese herbal medicine have not been well studied. In the present study, we administered the major active ingredients in Angll-infused mouse model, individually or synergistically, to interpret the potential mechanisms. Although GBE is a complex mixture of over 300 compounds, its major ingredients are $24 \%$ flavonoids and $6 \%$ ginkgolides. Flavonoids act as anti-oxidants, as well as anti-platelet aggregation by inhibiting arachidonic acid-based pathway [25]. As the specific antagonists of PAF, ginkgolides suppress platelet aggregation and activation [26]. Despite these many potential protective effects, flavonoids and ginkgolides individually or synergistically did not prevent aortic rupture. These findings demonstrate that GBE prevents Angll-induced aortic rupture through flavonoids and ginkgolides-independent effects. Taken together, herbal medicines may not be separated as single component in the prevention and treatment of cardiovascular diseases.

GBE reduces aortic dilation in calcium chloride-induced AAAs [13], but we did not find prevention of aortic dilation by GBE in Angll-induced AAAs. The major differences between the reported study and ours are different manipulations in different mouse strains. In a reported study [13], calcium chloride was applied directly to infrarenal aortas of normocholesterolemic mice. Aortic rupture has not been reported in this mouse model. In contrast, hypercholesterolemic mice infused with Angll subcutaneously, as used in our study, have high aortic rupture rate $[15,17,27]$. The conflicting findings also implicate different mechanisms of AAAs between these two mouse models, which may also represent complexity of this disease in humans.

In the clinical setting, preventing aortic rupture or progressive dilation is a desired outcome of therapy. Unfortunately, GBE did not prevent either aortic rupture or progressive dilation of established AAAs in Angll-infused mice. This finding further confirmed that it is challenging to prevent the progression of established AAAs due to its already formed complex disease status. GBE has been reported to attenuate atherosclerosis by endothelial protection, anti-oxidation activity, anti-aging, and antiinflammation [10]. However, our study demonstrated that GBE did not protect against atherosclerosis in Angll-infused models. Also, our present study failed to further look into the detailed molecular mechanisms due to limited tissue samples.

It hypothesizes GBE in combination with statins helps to treat patients with hyperlipidemia, however, there is no randomized, control clinical trials to prove it. GBE administration has been shown to reduce serum total cholesterol concentration in dietinduced hyperlipidemia rats, mediated by limiting cholesterol absorption, inactivating 3-hydroxy-3-methylglutaryl-coenzyme A, and regulating polyunsaturated fatty acid [28]. In the present studies, GBE administration, for either 1 month or 3 months, did not reduce serum total cholesterol concentrations in apoE-/mice. MMPs, especially for MMP-2 and MMP-9, have shown to be playing a critical roles in the pathological process of AAAs [29]. However, our previous study showed that MMP-9 deficiency leads to AAA formation in the absence of Angll, and augments Angllinduced aortic rupture and AAA formation [27]. In the present study, GBE did not alter serum concentrations MMP-2 and MMP-9, as well as MCP-1 and IL-6.
In conclusion, the present study showed that GBE, but not its individual active ingredients, suppressed aortic rupture in the early development of Angll-induced AAAs. These data suggest that GBE may be optimal for preventing aortic rupture in early stages for patients suffered with AAA.

\section{ACKNOWLEDGEMENTS}

This work was supported by grants from the National Natural Science Foundation of China (31371475, 31171392, and 81571932). We thank Dr. Jiyong Jing in the Department of Respiratory Therapy, Second Affiliated Hospital, Zhejiang University School of Medicine for helping statistical analyses.

\section{AUTHOR CONTRIBUTIONS}

X.-j.X. conceived and designed the experiments; X.-f.H., S.-Z.Z. and N.Z. performed the experiments; X.-j.X., H.L. and A.D. contributed new reagents or analytic tools; X.-f.H. X.-j.X. and Y.-y.Y. analyzed the data; X.-j.X., H.L. and A.D. wrote the manuscript.

\section{ADDITIONAL INFORMATION}

Competing interests: The authors declare no competing interests.

\section{REFERENCES}

1. Landenhed M, Engstrom G, Gottsater A, Caulfield MP, Hedblad B, Newton-Cheh C, et al. Risk profiles for aortic dissection and ruptured or surgically treated aneurysms: a prospective cohort study. J Am Heart Assoc. 2015;4:e001513.

2. Heikkinen M, Salenius JP, Auvinen O. Ruptured abdominal aortic aneurysm in a well-defined geographic area. J Vasc Surg. 2002;36:291-6.

3. Karthikesalingam A, Holt PJ, Vidal-Diez A, Ozdemir BA, Poloniecki JD, Hinchliffe RJ et al. Mortality from ruptured abdominal aortic aneurysms: clinical lessons from a comparison of outcomes in England and the USA. Lancet. 2014;383:963-9.

4. Daugherty A, Cassis LA, Lu H. Complex pathologies ofangiotensin II-induced abdominal aortic aneurysms. J Zhejiang Univ Sci B. 2011;12:624-8.

5. Liu J, Daugherty A, Lu H. Angiotensin II and abdominal aortic aneurysms: an update. Curr Pharm Des. 2015;21:4035-48.

6. Yoshimura K, Aoki H, Ikeda Y, Fujii K, Akiyama N, Furutani A, et al. Regression of abdominal aortic aneurysm by inhibition of c-Jun $\mathrm{N}$-terminal kinase. Nat Med. 2005;11:1330-8

7. Gopal K, Nagarajan P, Jedy J, Raj AT, Gnanaselvi SK, Jahan P, et al. Beta-carotene attenuates angiotensin II-induced aortic aneurysm by alleviating macrophage recruitment in Apoe(-/-) mice. PLoS ONE. 2013;8:e67098.

8. Seto SW, Krishna SM, Moran CS, Liu D, Golledge J. Aliskiren limits abdominal aortic aneurysm, ventricular hypertrophy and atherosclerosis in an apolipoprotein-E-deficient mouse model. Clin Sci. 2014;127:123-34.

9. Ghoshal S, Loftin CD. Cyclooxygenase-2 inhibition attenuates abdominal aortic aneurysm progression in hyperlipidemic mice. PLoS ONE. 2012;7:e44369.

10. Liu Q, Li J, Hartstone-Rose A, Wang J, Li J, Janicki JS, et al. Chinese herbal compounds for the prevention and treatment of atherosclerosis: experimental evidence and mechanisms. Evid Based Complement Alternat Med 2015;2015:752610.

11. Valli G, Giardina EG. Benefits, adverse effects and drug interactions of herbal therapies with cardiovascular effects. J Am Coll Cardiol. 2002;39:1083-95.

12. Unger M. Pharmacokinetic drug interactions involving Ginkgo biloba. Drug Metab Rev. 2013;45:353-85.

13. Wang L, Bai Y, Wang B, Cui H, Wu H, Lv JR, et al. Suppression of experimental abdominal aortic aneurysms in the mice by treatment with Ginkgo biloba extract (EGb 761). J Ethnopharmacol. 2013;150:308-15.

14. Huang $\mathrm{CH}$, Yang ML, Tsai CH, Li YC, Lin YJ, Kuan YH. Ginkgo biloba leaves extract (EGb 761) attenuates lipopolysaccharide-induced acute lung injury via inhibition of oxidative stress and NF-kappaB-dependent matrix metalloproteinase-9 pathway. Phytomedicine. 2013;20:303-9.

15. Daugherty A, Manning MW, Cassis LA. Angiotensin II promotes atherosclerotic lesions and aneurysms in apolipoprotein E-deficient mice. J Clin Invest. 2000;105:1605-12.

16. Lu H, Howatt DA, Balakrishnan A, Moorleghen JJ, Rateri DL, Cassis LA, et al Subcutaneous angiotensin II infusion using osmotic pumps induces aortic aneurysms in mice. J Vis Exp. 2015;103:53191.

17. Xie $X$, Wang $Y$, Zhang $S$, Zhang G, Xu Y, Bi H, et al. Chinese red yeast rice attenuates the development of angiotensin II-induced abdominal aortic aneurysm and atherosclerosis. J Nutr Biochem. 2012;23:549-56. 
18. Xie X, Lu H, Moorleghen JJ, Howatt DA, Rateri DL, Cassis LA, et al. Doxycycline does not influence established abdominal aortic aneurysms in angiotensin IIinfused mice. PLoS ONE. 2012;7:e46411.

19. Schmitz-Rixen T, Keese M, Hakimi M, Peters A, Bockler D, Nelson K, et al. Ruptured abdominal aortic aneurysm-epidemiology, predisposing factors, and biology. Lange Arch Surg. 2016;401:275-88.

20. Wild JB, Stather PW, Biancari F, Choke EC, Earnshaw JJ, Grant SW, et al. A multicentre observational study of the outcomes of screening detected subaneurysmal aortic dilatation. Eur J Vasc Endovasc Surg. 2013;45:128-34.

21. Lo RC, Lu B, Fokkema MT, Conrad M, Patel Vl, Fillinger $M$, et al. Relative importance of aneurysm diameter and body size for predicting abdominal aortic aneurysm rupture in men and women. J Vasc Surg. 2014;59:1209-16.

22. Ou HC, Hsieh YL, Yang NC, Tsai KL, Chen KL, Tsai CS, et al. Ginkgo biloba extract attenuates oxLDL-induced endothelial dysfunction via an AMPK-dependent mechanism. J Appl Physiol. 2013;114:274-85.

23. Tisato V, Zauli G, Rimondi E, Gianesini S, Brunelli L, Menegatti E, et al. Inhibitory effect of natural anti-inflammatory compounds on cytokines released by chronic venous disease patient-derived endothelial cells. Mediat Inflamm. 2013;2013:423407.
24. Liu O, Jia L, Liu X, Wang Y, Wang X, Qin Y, et al. Clopidogrel, a platelet P2Y12 receptor inhibitor, reduces vascular inflammation and angiotensin II inducedabdominal aortic aneurysm progression. PLoS ONE. 2012;7:e51707.

25. Pietta PG. Flavonoids as antioxidants. J Nat Prod. 2000;63:1035-42.

26. Lamant V, Mauco G, Braquet $P$, Chap H, Douste-Blazy L. Inhibition of the metabolism of platelet activating factor (PAF-acether) by three specific antagonists from Ginkgo biloba. Biochem Pharmacol. 1987;36:2749-52.

27. Howatt DA, Dajee M, Xie X, Moorleghen J, Rateri DL, Balakrishnan A, et al. Relaxin and matrix metalloproteinase- 9 in angiotensin Il-induced abdominal aortic aneurysms. Circ J. 2017;81:888-90.

28. Zhang Q, Wang GJ, A JY, Wu D, Zhu LL, Ma B, et al. Application of GC/MS-based metabonomic profiling in studying the lipid-regulating effects of Ginkgo biloba extract on diet-induced hyperlipi-demia in rats. Acta Pharmacol Sin. 2009;30:1674-87.

29. Longo GM, Xiong W, Greiner TC, Zhao Y, Fiotti N, Baxter BT. Matrix metalloproteinases 2 and 9 work in concert to produce aortic aneurysms. J Clin Invest. 2002;110:625-32. 